\title{
Conceito de entropia e ensino da Química *
}

\section{1 - INTRODUÇÃO}

Porquê este título para uma plenária dum encontro de Educação em Química envolvendo profissionais tanto do Ensino Secundário como Terciário?

Antes de mais diga-se que o tipo de problema que se aborda - desenvolvimento curricular de um tópico, usando modelos adequados aos aprendizes - é apenas uma das muitas questðes que se pð̄em no panorama geral da Educação em Química. Outros tipos de problemas são por exemplo a linguagem da instrução e a compreensão do pensamento do aprendiz que até certo ponto serão abordados na outra lição plenária, justificando-se, assim, aqui o tratamento dum tópico curricular de forma a conciliar a clareza e a correcção dos conceitos. Este problema de procura de modelos simplificados da realidade é, já o reconhecia Einstein, particularmente difícil, pois que se corre o risco de " $^{5}$ oferecerem ao aprendiz aspectos superficiais ou alusðes vagas escondendo o cerne do problema e criando a ilusão de compreensão"'. O que se deve fazer é realmente ir ao cerne da ideia escolhendo modelos que a ilustrem mas que sejam isentos de complicaçðes. Como se pode compreender as soluçðes para tais questðes não são únicas e carecem de uma avaliação criteriosa.

E quanto ao problema concreto - ensino do Conceito de Entropia? Porquê abordá-lo? Porquê já que tal conceito apenas faz parte do programa do $12 .^{\circ}$ ano (uma parte que aliás raramente é dada pelos professores) e na Universidade quase só aparece em cadeiras não introdutórias e abordado de uma forma clássica, não esclarecedora dos fenómenos químicos a nível microscópico? Talvez precisamente por isso, por este estado de coisas e por cada vez mais se reconhecer a importância da introdução cedo na educação dos alunos do Conceito de Entropia e suas aplicaçðes e por outro lado por se reconhecer a sua dificuldade e também a ausência de grande preparação dos docentes sobre ele, é que se escolheu este tema. A inegável dificuldade do assunto gerou intensa polémica sobre a sua inclusão nos currículos elementares, tendo acabado por quase universalmente se aceitar a necessidade da sua inclusão, mesmo a nível secundário, em virtude da extrema importância da entropia e do segundo principio da Termodinâmica.

Criou-se assim um forte incentivo para a pesquisa de modelos simplificados para a abordagem do problema, parte dos quais serão referidos mais adiante.

Os argumentos que levam à inclusão curricular baseiam-se na importância do tema que é inegável como base de critério de espontaneidade e de equilibrio tanto na Física como na Química, permitindo o não recurso a falsos principios muito generalizados nestas Ciências, como o de minização de energia potencial e permitindo ainda estudar a analogia entre os equilibrios físicos e químicos, o que é extremamente útil na integração destas Ciências. A aplicação dos critérios de espontaneidade aos fenomenos biologicos e às formas disponiveis de energia, bem como a entrada na linguagem de todos os dias - um pouco devido à vulgarização da informática - de termos relacionados com a entropia e o $2 .^{\circ}$ princípio, são também razðes que levam à inclusão do tema o mais cedo possivel no curriculum. Deve dizer-se, para além disso que há razōes de estratégia de desenvolvimento curricular em Quimica, que impõem uma modificação radical da aproximação convencional, ainda hoje dominante em muitos dos currículos portugueses e que consiste na separação dos aspectos estruturais e dinâmicos da Química, sendo esta estratégia substituída por uma de integração gradual dos aspectos dinâmicos com os estruturais, sendo para tal tipo de estratégia absolutamente essencial a introdução do conceito de entropia e a sua caracterização duma forma microscópica. Esta caracterização leva a uma noção microscópica de temperatura com base nas características estatísticas da distribuição da energia pelas partículas ${ }^{*}$, que por sua vez leva ao factor de Boltzmann, que permite a introdução da Cinética Química.

Está muito longe, no entanto, a existência de unanimidade quanto à maneira de se introduzir a noção de entropia, sendo disso testemunho indesmentivel as diferentíssimas formas de enunciar o $2 .^{\circ}$ princípio da Termodinâmica. A forma convencional da sua introdução, através dos ciclos de Carnot adaptados às máquinas térmicas, não serve para a Química. Para a Química idealmente servirá um tipo de introduçâo que reflicta as consequências microscópicas das aplicação do $2 .^{\circ}$ principio e assim é que, tendo presentes as dificuldades conceptuais duma abordagem do problema em termos de mecânica estatística, não só pela complexidade dos formalismos, mas também e principalmente pela conhecida aquisição tardia do esquema de probabilidade por parte do aprendiz ${ }^{13}$, a solução preconizada para o tratamento da ideia de entropia e do segundo principio da Termodinâmica, a nivel introdutório e dentro dos curriculos da Química, é a seguinte (inspirada no modelo de Bruner ${ }^{4}$ de curriculo espiral):

\footnotetext{
- Faculdade de Ciências do Porto, Praça Gomes Teixeira, Porto.

- Comunicação apresentada no VIII Encontro da SPQ (Braga, Abril de 1985).

- Portanto independente da Teoria Cinética dos Gases.
} 


\section{$1 .^{\circ}-$ Nível de $8 .^{\circ}$ e $9 .^{\circ}$ anos}

$A$ nivel de $8 .^{\circ}$ e 9. ${ }^{\circ}$ anos, possivelmente em continuidade com os programas de Ciências da Natureza, propõe-se a familiarização dos alunos com o princípio da irreversibilidade dos fenónemos espontâneos, a que deverá ser dada tanta importância como ao princípio de conservação da energia e que deve ser interpretado em termos da tendência que as partículas e a energia que elas possuem têm de ocupar o maior espaço possivel *.

Conceitos não muito fáceis, como espontaneidade, que deverá ser distinguido de rapidez, e irreversibilidade, que deverá ser distinguido de irretornabilidade, começam a aparecer e a ser caracterizados.

$O$ conceito de entropia, a aparecer aqui, seria apenas como uma propriedade de matéria por intermédio da qual os cientistas medem o estado de dispersão das partículas e energia dos sistemas e que, portanto, aumentará, para o Universo (sistema e meio exterior no seu conjunto), em todas as reacçðes espontâneas.

Poderão a título de exemplo ser fornecidas entropias molares (sem grande atenção para as unidades em que vêm expressas) de algumas substâncias, nesta fase nitidamente inactiva da aprendizagem do conceito.

É também importante que a entropia seja caracterizada como propriedade extensiva, sem utilizar este nome, bastando usar os conhecimentos de matemática dos alunos para dizer que a entropia dum conjunto, que é a reunião de vários outros conjuntos, é a soma das entropias desses subconjuntos.

\section{$2 .^{\circ}-$ Nivel do $10 .^{\circ}$ e $11 .^{\circ}$ anos}

A nivel do $100^{\circ}-11 .^{\circ}$ anos preconiza-se um aprofundamento e operacionalização destas noçðes, sem contudo ainda se entrar numa definição microscópica de entropia em termos de contagem de microestados, embora esse seu significado esteja sempre presente ${ }^{*}$.

Assim, é que, procurando responder à pergunta Porque mudam as coisas? - se chega à conclusão que as mudanças naturais são sempre acompanhadas por um aumento na dispersão da energia e que as reacçðes quimicas não fogem à regra, actuando pois como dispersantes de energia.

Uma reacção exotérmica (a termoquímica** supð̃e-se dada) envolvendo um gás como reagente é tomada (oxidação do Ferro) e explica-se que a reaç̧ão se dará ou não, dependendo dum balanço entre o consumo do gás que leva a uma localização da energia e a dispersão da energia que é absorvida pela vizinhança (meio exterior) aquando da reacção. Neste caso esta última tendência ganha e o ferro (devagar ou depressa, isso não pode ser garantido) enferruja mesmo.

A entropia e o segundo princípio da termodinâmica são então introduzidos, aparecendo aquela como uma medida da dispersão caótica da energia, que os termodinâmicos medem como $\Delta \mathrm{S}=\mathrm{qr} / \mathrm{T}$ para qualquer transformação, em que qr é o calor transferido reversivelmente para o sistema.

Este reversivelmente quer dizer com muito cuidado, sem deixar que se desenvolvam diferenças de temperatura entre sistema e meio exterior.

O segundo princípio enunciado como a entropia do universo aumenta no decurso de qualquer mudança natural leva sempre à consideração do que acontece no sistema e na vizinhança. Depois de apresentadas as entropias molares de algumas substâncias, agora com as suas unidades já justificadas (pela definição) calcularảm-se variaçðes de entropias nos sistemas para o caso de certas reaç̧ðes como por exemplo o enferrujamento do Ferro, chegando-se a um valor negativo e a monomerização de $\mathrm{N}^{+} \mathrm{OR}$, chegando-se a um valor positivo.

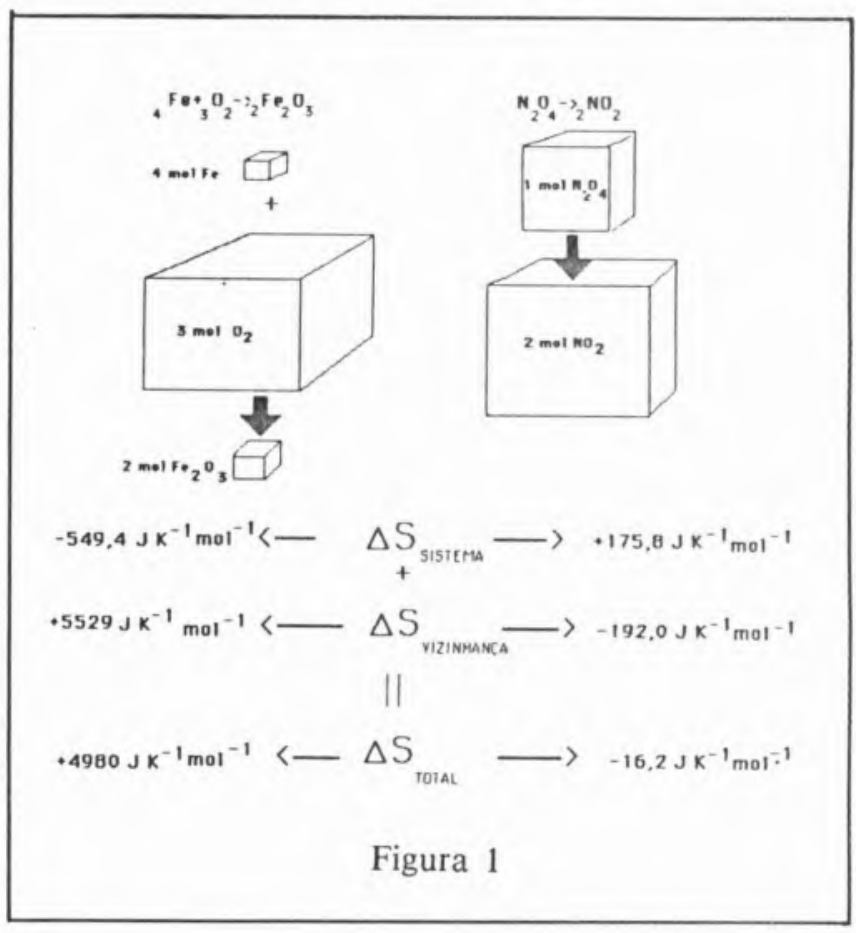

Explica-se, então, que os termodinâmicos calculam a variação da entropia da vizinhança como $-\Delta \mathrm{H} / \mathrm{T}$ e obtêm-se então para as variaçð̃es de entropias totais valores no $1 .^{\circ}$ caso positivo e grande em valor absoluto e que se interpreta como sinal da reacção se dar completamente e no segundo caso negativo, mas pe-

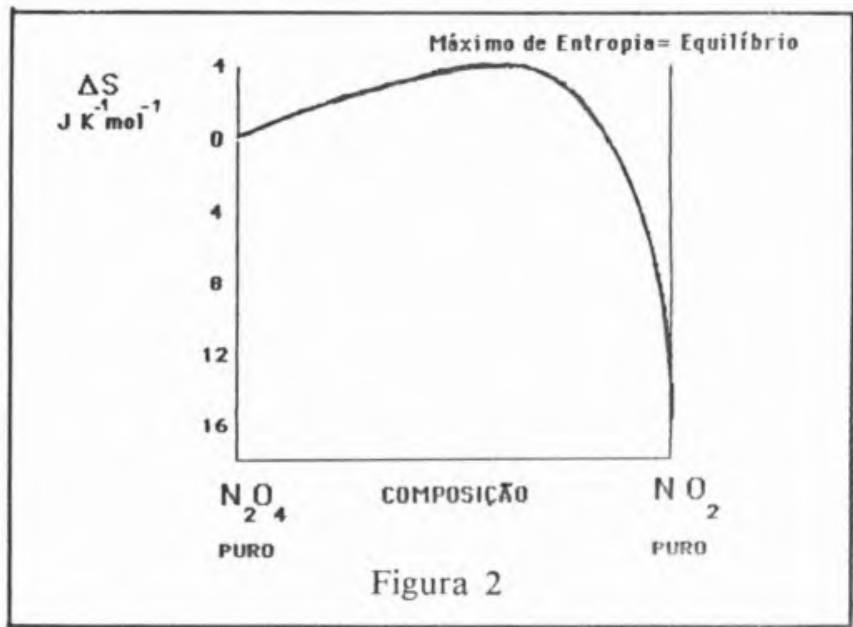

\footnotetext{
* Na realidade há quem advogue que neste momento é contra-intuitivo e ineficaz o principio de maximização da desordem e que se deve introduzir antes um principio de tendência para a uniformidade (Sameness) de todas as caracteristicas físicas ${ }^{16}$.

- A aproximação aqui descrita é essencialmente inspirada em Atkins ${ }^{1}$.

** Note-se no entanto as grandes dificuldades associadas à apren-
} dizagem do conceito de calor ${ }^{11}$. 
queno em valor absoluto, levando à ideia de equilibrio químico que seria atingido para determinada proporção de $\mathrm{NO}^{+}$e $\mathrm{N}^{+} \mathrm{OR}$ relativamente à qual a entropia total teria um máximo e para a qual tenderiam todas as misturas de $\mathrm{NO}^{+} \mathrm{N}^{+} \mathrm{OR}$.

Em vez de se ter o incómodo de consultar dois tipos de tabelas: a de entropias para a variação de entropia do sistema e a de entalpias para depois de dividida por $T$ e trocada de sinal dar a variação da entropia da vizinhança, lógico é tentar unificar esses dados o que se consegue através duma função $-\mathrm{T} \Delta \mathrm{S}_{\text {total, }}$, chamada função de Gibbs da reacção e que se denota por $\Delta \mathrm{G}$. É fácil de ver que

$$
\Delta \mathrm{G}=\Delta \mathrm{H}-\mathrm{T} \Delta \mathrm{S}
$$

Esta função, tambem designada por energia livre de Gibbs, tem imensa importância na Química, já que serve duma forma prática para prever se as reacçōes têm tendência para ocorrer ( $\Delta \mathrm{G}$ negativo) podendo ser exotérmicas ou endotérmicas $(\Delta \mathrm{H}$ negativo e positivo respectivamente) e ainda devido à ligação que os termodinâmicos estabelecem entre esta grandeza e o valor das constantes de equilibrio $\Delta \mathrm{G}=-\mathrm{RT} \ln \mathrm{K}_{\text {eq }}$.

Um outro aspecto talvez não menos importante desta grandeza é o significado que os termodinâmicos lhe encontram como a quantidade máxima de trabalho que pode ser obtido de uma reacção, isto se esta for conduzida de forma a perder-se para o exterior apenas a quantidade de calor necessário para compensar a variação de entropia do sistema.

$\Delta \mathrm{G}$ aparece assim como energia disponível para produzir trabalho e as suas aplicaçðes à biologia e à discussão dos recursos energéticos seguem-se logicamente.

\section{$3 .^{\circ}$ - Nível de $12 .^{\circ}$ ano $-1 .^{\circ}$ ano da Faculdade}

A este nivel impð̃e-se já uma abordagem estatistica do conceito de entropia.

É a escolha desta abordagem, perante as múltiplas opçðes que existem, dada a impossibilidade do tratamento plenamente sofisticado do problema relegado para cadeiras do fim do curso, que vai ocupar o resto desta palestra. Veremos na próxima secção as opçð̃es e na seguinte descrevemos a que nos parece ser mais indicada.

\section{2 - OS VÁRIOS MODELOS ESTATÍSTICOS}

Embora associando a entropia à medida da dispersão da energia a sua definição foi até agora a da Termodinâmica Clássica. Para que todas as consequências da distribuição da energia pela matéria sejam bem entendidas, não só as que dizem respeito ao equilibrio quimico e à determinação do sentido espontâneo das reacçðes exige-se, em determinada altura, que iremos situar entre o $12 .^{\circ}$ Ano e o $1 .^{\circ}$ Ano da Faculdade, uma definição microscópica da entropia.

Tal é necessário, mesmo em virtude da própria natureza da Quimica, cujas bases nas Ciências Físicas são, de acordo com Bent ${ }^{2}$, a Mecânica Quântica e a Mecânica Estatística.

Embora para as temperaturas correntes na crosta terrestre os aspectos quânticos da energia electrónica sejam separáveis dos aspectos estatísticos, já que há apenas ocupação apreciável dos niveis quânticos mais baixos, outro tanto não se poderá, dizer de tal separa- ção no que diz respeito aos movimentos vibracionais, rotacionais e translacionais.

Assim é que, sem sombra de dúvida, uma base superior para a compreensão dos conceitos da Química deve ser simultaneamente quântica e estatística.

É por isso muito lastimável que a generalidade dos nossos cursos apenas dê ênfase aos aspectos quânticos talvez por os aspectos estatisticos envolverem um formalismo ainda mais elaborado. A solução do problema está, como já foi dito, no uso de um modelo simplificado, que ataque o âmago dos conceitos e provoque a verdadeira compreensão e não apenas a ilusão de compreensão dos fenómenos envolvidos.

Muito rapidamente, porque não se dispðe de tempo para mais, passam-se em revista os vários modelos simplificados que têm servido de base à introdução do raciocinio estatístico nas Ciências Físicas.

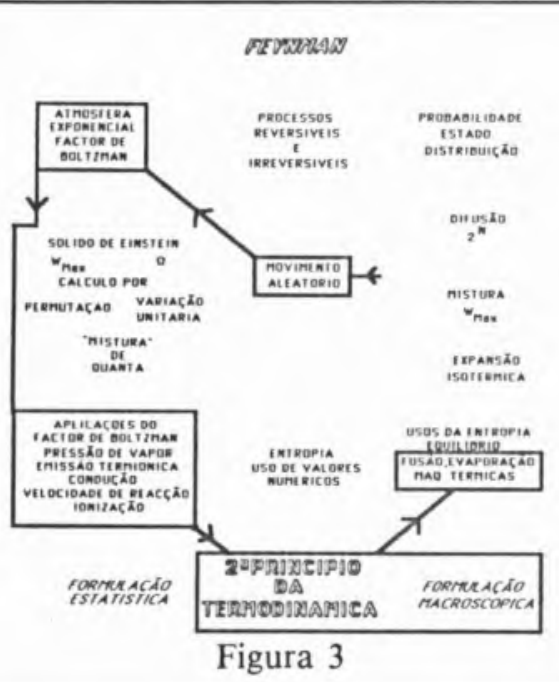

Feynman ${ }^{6}$ (vide figura 3) coloca toda a sua ênfase numa artificial e artificiosa atmosfera exponencial da qual deduz o factor de Boltzmann, cujos usos, mais fisicos do que quimicos, não chega a ligar ao segundo principio da termodinâmica, entretanto introduzido convencionalmente a partir dos ciclos de Carnot.

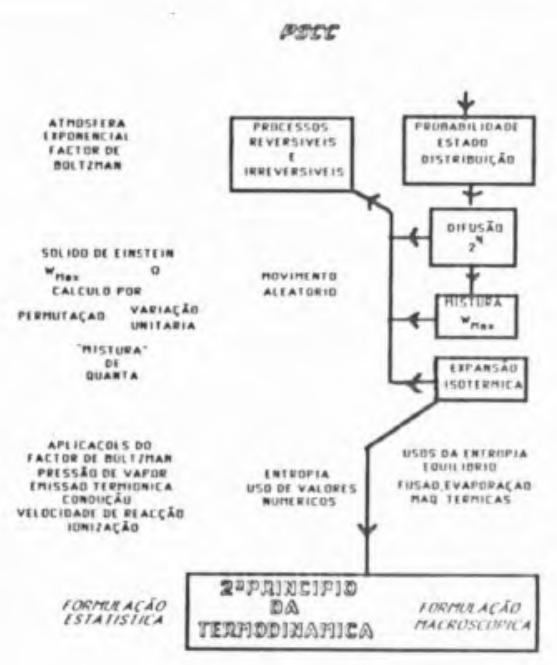

Figura 4 
A estratégia do PSSC ${ }^{14}$ (vide figura 4) por outro lado parte da difusão, passando à expansão isotérmica de gases, relacionando tudo com o número de microestados associados à configuração mais provável do sistema - $\mathrm{W}_{\text {max }}$ - e tendo em conta a distinção entre processos reversíveis e irreversíveis, ligando tudo isto a uma formulação do $2 .^{\circ}$ princípio que é ao mesmo tempo estatística e macroscópica.

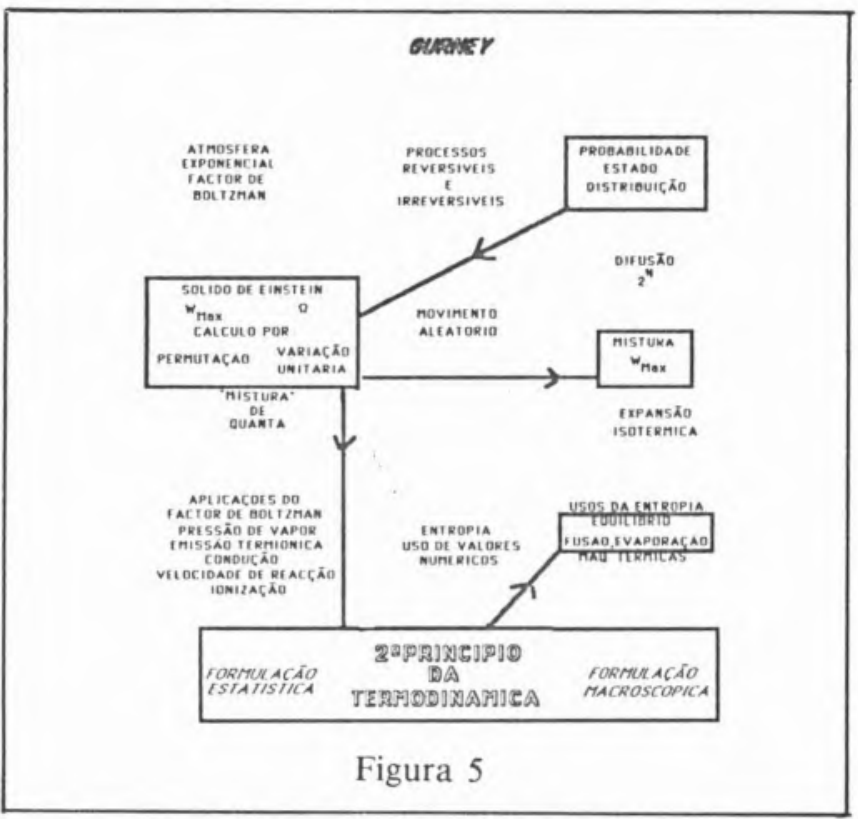

A aproximação de Gurney ${ }^{7}$ (vide figura 5) baseia-se no sólido de Einstein, para o qual se calcula também o número de microestados associados à configuração mais provável - $\mathrm{W}_{\text {max }}-\mathrm{o}$ que leva também a uma formulação estatística do segundo princípio, sendo depois explicados alguns dos usos da entropia, tanto físicos como químicos.

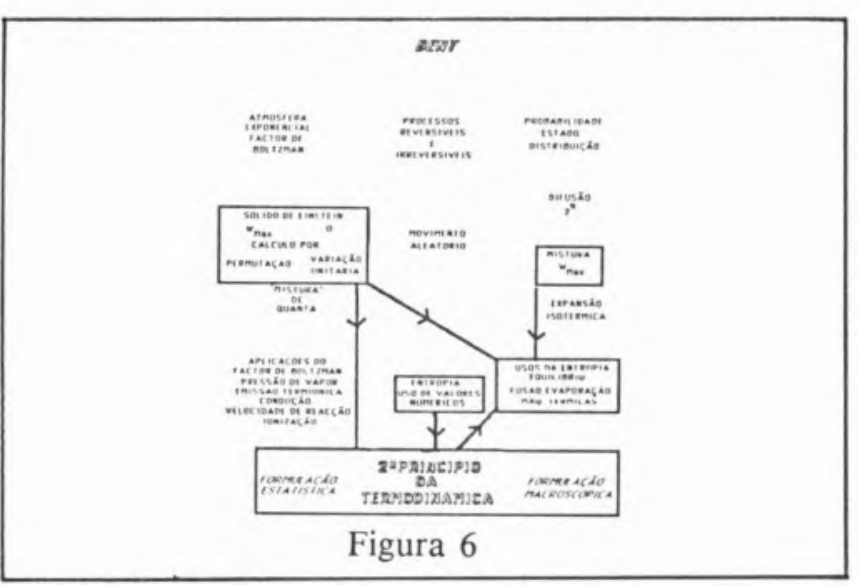

A estratégia de Bent ${ }^{2}$ (vide figura 6) baseia-se no sólido de Einstein com o cálculo do número de microestados por variação unitária e por outro lado na ideia de mistura. Ambos esses aspectos levam aos usos mais importantes da Entropia cujos valores entretanto para várias substâncias concretas são dados, permitindo um estabelecimento do $2 .^{\circ}$ princípio, duma forma simultaneamente microscópica e macroscópica.

A estratégia de Ogborn ${ }^{10}$ (vide figura 7), cujas linhas gerais seguiremos, usa os aspectos mais importantes da estratégia de Bent:

a) No uso do sólido de Einstein para caracterizar a en-

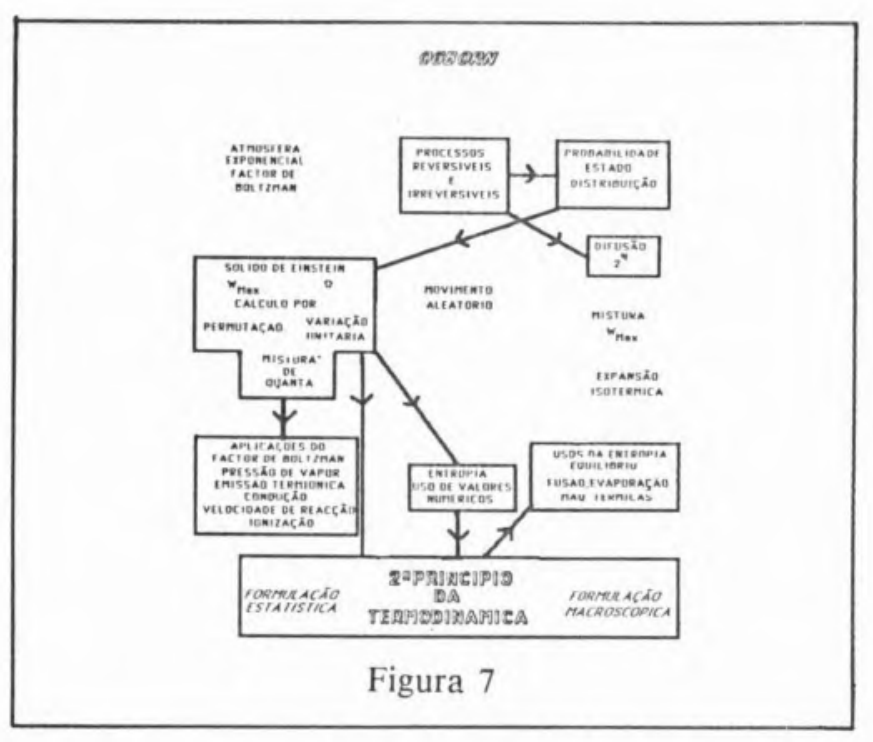

tropia de origem térmica não aplica o conceito de $\mathrm{W}_{\text {gáx }}$ - número de microestados associados à distribuiçã̃o mais provável, mas $\operatorname{sim} \Omega$ - número total de microestados acessiveis do sistema, sendo os cálculos feitos por mudança unitária e por uma estratégia própria, dita de baralhamento de quanta ${ }^{3}$ (quantum Shuffling).

b) Em vez da mistura ou da expansão isotérmica, usa a difusão para caracterizar a entropia de posição.

c) Utiliza, tal como Bent, os valores numéricos da entropia.

d) Aplica as regularidades da distribuição da energia no sólido de Einstein, não só para desenvolver aspectos de equilibrio, como também, através do factor de Boltzmann para tratar aspectos cinéticos.

Só a facilitação destas ligaçðes dos aspectos cinéticos aos termodinâmicos e dos equilibrios físicos aos químicos justifica a sua adopção em Química.

\section{3 - AS LINHAS GERAIS DA INTRODUÇÃO ESTATISTICA AO CONCEITO DE ENTROPIA E SUAS APLICAÇÕES}

Em primeiro lugar deve dizer-se que esta introdução, seguindo as linhas gerais de Ogborn ${ }^{10}$ é inspirada na muito recente revisão dos materiais curriculares feita pela Fundação Nuffield em Inglaterra ${ }^{8}$, obedecendo à ideia geral da integração dos aspectos estruturais com os dinâmicos, de forma que os vários aspectos dinâmicos são tratados, em intervençðes mais ou menos longas, diluidas pelo conjunto do programa, cujo esquema organizacional se mostra na figura 8 . Assinaladas com numeração romana aparecem as intervenções -8 ao todo - que introduzem as ideias dinâmicas no currículo. Vejamo-las com um bocadinho mais de detalhe, particularmente duas delas (II e III).

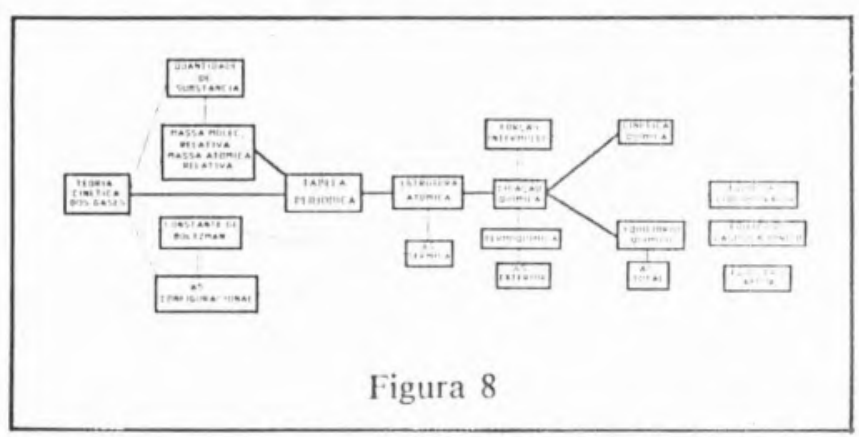


2. ${ }^{a}$ Intervenção - as moléculas não de importam. Variação de entropia de posição ou configuração

Aproveitando-se o tratamento da teoria cinética dos gases, um dos primeiros tópicos do currículo, introduz-se a muito importante ideia de que as moléculas vão ocupar o espaço por critérios meramente probabilísticos.

Usa-se, para concretizar, um conjunto de partículas identificáveis que se podem distribuir pelas duas metades duma caixa (vide figura 9), o que pode ser realizado pelos lançamentos de um dado, mudando-se de lado a partícula cujo número corresponde ao indicado pelo dado. $\mathrm{O}$ número de maneiras possiveis é contado para vários casos: $2^{6}=64$ para 6 partículas, $2^{100} \cong 10^{30}$ para 100 particulas e um número muito grande $2^{6 \times 10^{23}}$ para uma mole de partículas.

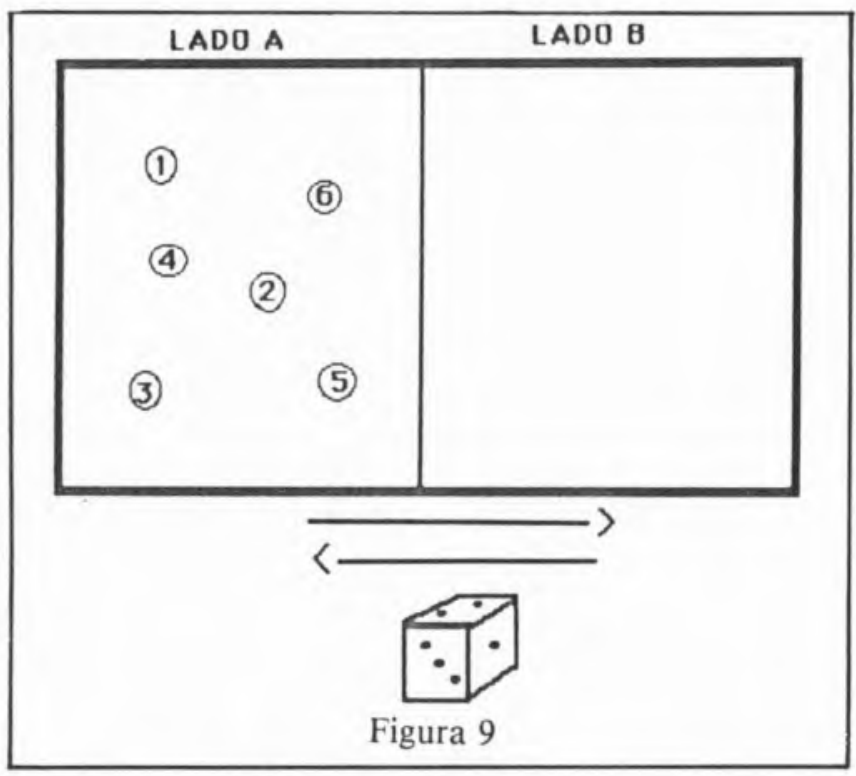

A introdução de logaritmos para contabilizar o número de maneiras é encorajada, não só para diminuir os números gigantescos, mas também e muito principalmente por substituir uma grandeza multiplicativa como é o número de maneiras ou de microestados, por uma grandeza aditiva, o respectivo logarítmo. Passa-se então para o caso da contagem do número de microestados de uma mole de Néon que dobra o seu volume, afirmando que

$$
\mathrm{W}_{2} / \mathrm{W}_{1}=2^{6 \times 10^{23}}
$$

resultado que é essencialmente correcto, supondo a idealidade do gás já que neste caso não temos que ter em conta vibraçðes nem rotaçðes e ainda embora os valores de $\mathrm{W}_{2}$ e W $\mathrm{W}_{1}$ não possam ser contados como os de partículas discerníveis, já que como átomos o não são, $\mathrm{W}_{2} / \mathrm{W}_{1}$ é o mesmo sejam as partículas discerniveis ou não.

A enormidade do número faz-nos usar o seu logaritmo

$$
\ln \left(\mathrm{W}_{2} / \mathrm{W}_{1}\right) \cong 4 \times 10^{23}
$$

O uso de k (constante de Boltzmann) que tinha sido já encontrada como constante dos gases perfeitos para uma molécula, traz-nos

$$
\mathrm{k} \ln \frac{\mathrm{W}_{2}}{\mathrm{~W}_{1}}=6 \mathrm{JK}^{-1}
$$

A quantidades como esta $\mathrm{k} \Delta \mathrm{ln} \mathrm{W}$ dá-se o nome de variações de entropia e resultam numa maneira cómoda de contabilizar a variação do número de arranjos ou microestados dos sistemas.

Para se ter uma ideia mais concreta, pode-se ver em tabelas a entropia molar padrão do árgon $\mathrm{S}^{\theta}=146 \mathrm{~J} \mathrm{~K}^{-1}$ mole $^{-1}$ concluindo que esta variará de 140 a $152 \mathrm{~J} \mathrm{~K}^{-1}$ mole $^{-1}$ quando variamos a pressão de metade para o dobro da pressão padrão.

3. ${ }^{a}$ Intervenção - a energia tembém não se importa. Entropia de origem térmica

Aproveitando-se o tópico estrutural do programa em que se discute a estrutura electrónica dos átomos (vidé figura 8), refere-se que não só os electrðes têm a sua energia quantizada, mas também as moléculas sujeitas a vibraçðes e rotaçð̄es. Só que, para estas, ao contrário dos electrōes, a energia térmica disponível às temperaturas da superfície da Terra é suficiente para produzir a ocupação significativa de estados para além do fundamental. Dai o ser tão importante como o problema tratado anteriormente de estudar o número de combinaçðes de moléculas de gás*, o estudar o número de combinaçð̃es dos quanta de energia pelas partículas. Com vista a eliminar todas as complicaçðes, usa-se um modelo extremamente simplificado, chamado sólido de Einstein, constituído por $\mathrm{N}$ vibradores harmónicos, sem acoplamento, sendo os niveis energéticos igualmente espaçados duma quantidade $-\epsilon-0$ quantum. Tratar-se-á de estudar as combinaçðes possiveis dos q quanta pelos $\mathrm{N}$ osciladores, podendo, por cálculos rápidos, sermos levados a concluir que os números q e $\mathrm{N}$ são da mesma ordem de grandeza**.

Note-se, que relativamente a este modelo os sólidos reais além de terem uma energia no estado fundamental não nula (energia do ponto zero) têm espaçamentos não idênticos entre os niveis quânticos. Isto no entanto não prejudica o valor das conclusões que vamos tirar! Estudam-se assim o número de combinaçðes: microestados de 2 moléculas com 4 quanta e o que acontece quando se passa para 5 quanta, e ainda de 3 moléculas com 3 quanta, etc...

Para 100 moléculas com 100 quanta já há $8 \times 10^{59} \mathrm{com}-$ binaçðes e para o caso de $10^{23}$ moléculas com $10^{23}$ quanta, o número de combinaçð̌es, é já tão grande que justifica o mesmo tipo de estratagema do que o usado para o número de maneiras de moléculas gasosas. Assim surge-nos a entropia de origem térmica:

$$
\mathrm{S}=\mathrm{k} \ln \mathrm{W}
$$

que para o caso é:

$$
\mathrm{S}=1,9 \mathrm{~J} \mathrm{~K}^{-1}
$$

da mesma ordem de grandeza dos encontrados anteriormente.

As propriedades da distribuição da energia no sólido de Einstein são subsequentemente investigadas, usando-se uma grelha de $6 \times 6$ espaços e 36 marcadores, representando cada um, um quantum de energia e inicialmente distribuídos um por cada um dos quadrados

\footnotetext{
* Na realidade o problema tratado anteriormente está relacionado com a quantização dos niveis translacionais que se dispōem quase num continuo.

** Note-se que para gases perfeitos $3 / 2 \mathrm{kT}$ é a energia cinética média das particulas.
} 
da grelha. Dois dados diferentemente coloridos darão em lançamentos sucessivos a posição do quadrado que perderá um quantum de energia e a do que a receberá (no caso do primeiro quadrado já estar vazio repete-se o lançamento).

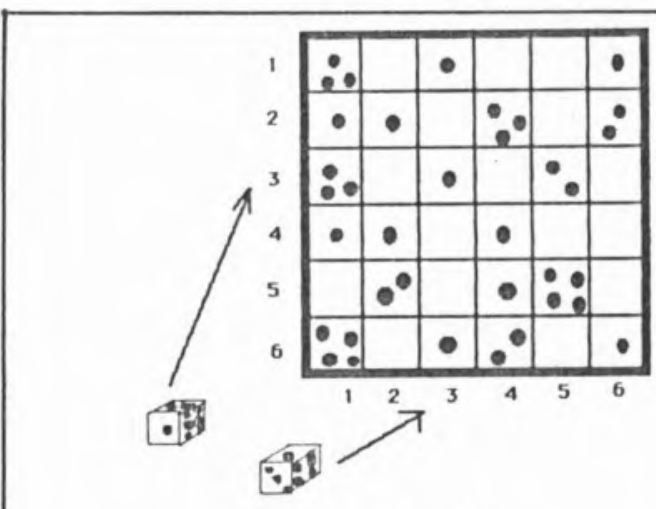

Figura 10

Ao fim de algum tempo a posição dos marcadores no tabuleiro, poderá ser a indicada na figura 10 e fazendo um gráfico do número de osciladores e dos respectivos niveis de ocupação obtém-se qualquer coisa como a figura 11. Tomando nota das configuraçðes que vamos tendo e calculando a sua probabilidade de ocorrência verifica-se (vidé apêndice 1) que se atinge um máximo, a configuração mais provável, a que corresponde um número máximo de microestados à volta do qual, com pequenas oscilaçðes, o sistema existe.

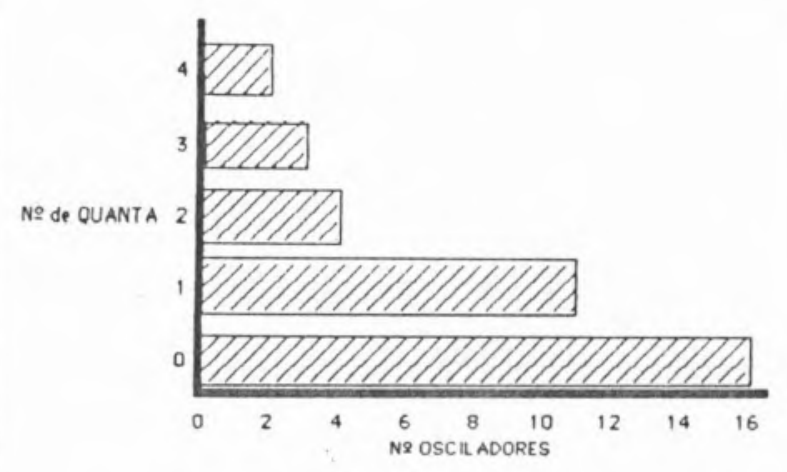

Figura 11

Esta é a forma mais simples de equilibrio - o equilibrio térmico - que tem de comum com todas as outras a sua realização corresponder a um máximo de probabilidades e portanto de entropia.

Este exercício, ou com vantagem uma simulação análoga em microcomputadores onde se poderá ir com facilidade para uma grelha de $30 \times 30$, por exemplo, permitirá observar um outro aspecto extremamente importante: é que os niveis de ocupação se dispð̄em em progressão geométrica de razão $\mathrm{r}$ (vidé apêndice 2); com umas contas muito simples baseadas em somas de séries pode verificar-se que

$$
r=1+\frac{N}{q}
$$

o que é precisamente também - uso da técnica da va- riação unitária ${ }^{10}$ - o número porque resulta multiplicado o número de microestados do sistema quando este absorve 1 quantum de energia.

Com este significado para o valor da razão da progressão da ocupação dos níveis, fácil é alimentar esperanças de com esse valor ou melhor o seu inverso caracterizar a temperatura de sistemas, já que mesmo simulaçð̌s em computador permitem dizer (vide figura 12) que relativamente por exemplo a um sistema de 100 partículas +100 quanta o $1 / \mathrm{r}$ é menor que o $1 / \mathrm{r}$ de 100 partículas +200 quanta e que o valor de equilibrio do $1 / \mathrm{r}$ correspondendo a 200 partículas +300 quanta é intermediário entre os dois. Em vez de se usar 1/r usa-se para definição de temperatura absoluta, no entanto, $\epsilon / \mathrm{k} 1 \mathrm{nr}$, o que tem vantagens para além do mais, de a temperatura variar entre 0 e $\infty$ e não entre 0 e 1 , como seria se se escolhesse $1 / \mathrm{r}$.

Esta forma de equilibrio simulado em computador, para além de nos permitir dar esta definição de temperatura, permite imediatamente estabelecer o $2 .^{\circ}$ principio da Termodinâmica com base na simples observação

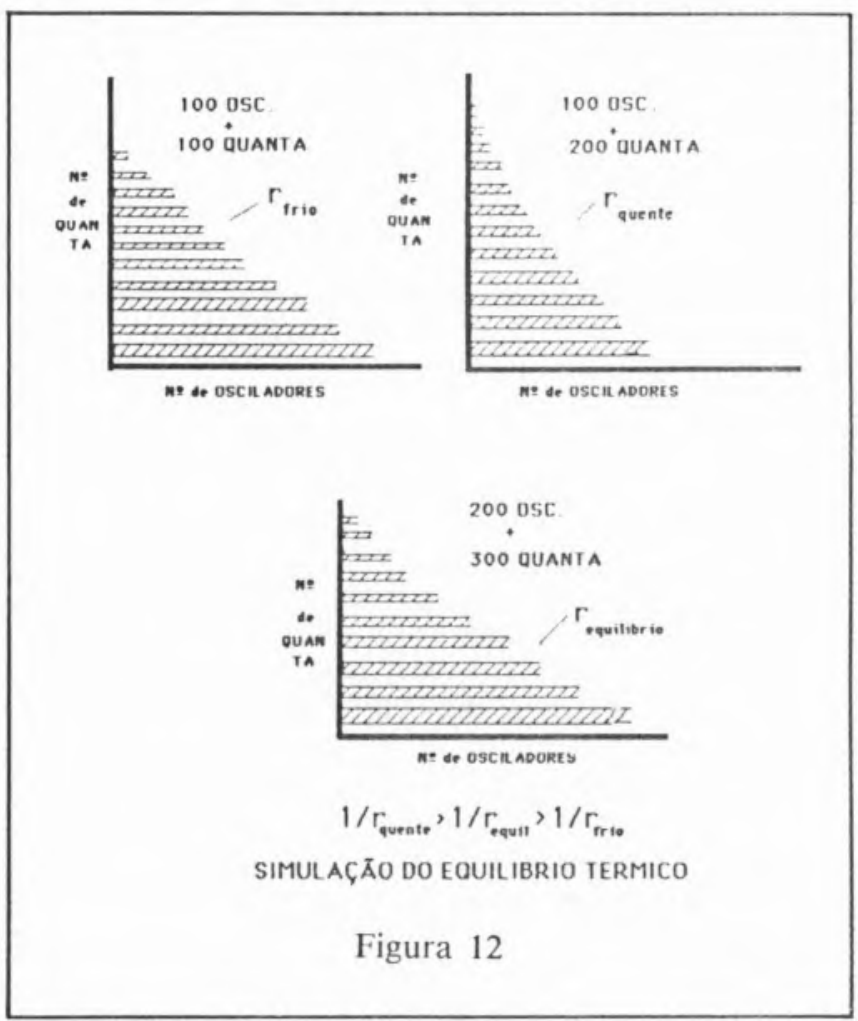

de que $1 / \mathrm{r}_{\text {quente }}>1 / \mathrm{r}_{\text {frio }}$ e de que o efeito observável do equilibrio é a passagem de quanta, do corpo quente para o frio, de modo a estabelecer-se um $1 / \mathrm{r}$ intermediário (vide figura 12). É que retomando o significado já visto de $r$, por cada quantum de energia que sai do corpo quente o número de microestados deste resulta dividido por um número menor do que aquele que multiplica o número de microestados do corpo frio, sendo como não pode deixar de ser o número final de microestados superior ao inicial.

As duas outras grandes consequências deste modelo, generalizável para casos mais complexos são o facto de através desta definição de temperatura se poder chegar a um resultado muito mais geral (vide apêndice 3):

$$
T=\frac{d U}{d S}
$$

e ainda a um resultado extremamente importante que é o número $n_{i}^{1}$ de partículas existentes com uma energia 
superior a uma determinada - E - e que caracteriza no fundo a probabilidade do sistema receber ou ceder calor do exterior e que tem uma importância fundamental na cinética química

$$
\frac{n_{i}}{n_{i-1} r}=\frac{1}{N}=e-\epsilon / K T \rightarrow \frac{n_{i}^{1}}{N}=e-E / K T
$$

Nos sistemas reais esta razão é dada não só por $e^{-E / k T}$ mas também por um termo quântico*

\section{3 - AS RESTANTES INTERVENÇÕES}

As restantes intervençס̄es (vide figura 8) têm por finalidade a aplicação das ideias desenvolvidas anteriormente aos problemas dos equilíbrios líquido-vapor e quimico e da cinética química.

Antes disso, no entanto, aproveita-se um capitulo de Termoquímica, para se justificar o processo usual de contabilização da variação de entropia do meio exterior por

$$
-\frac{\Delta \mathrm{H}}{\mathrm{T}}
$$

já que esse meio exterior, por definição, não sofre mais modificaçð̃es do que uma redistribuição da energia térmica que recebe do sistema, sendo esta, para reacçð̃es a pressão constante igual a $-\Delta \mathrm{H}$.

As duas parcelas que contabilizam a variação da entropia do Universo



não correspondem, é importante que se frise, a qualquer tipo de compromisso entre dois principios: um de diminuição de energia e outro de aumento de entropia, mas sim a um único: o de aumento da entropia do Universo. O hidrogénio não existe na superfície da Terra sob a forma molecular por causa dos electrões ocuparem a posição de menor energia possível, correspondente à orbital molecular ligante, mas porque ao fazê-lo, libertam uma quantidade tal de energia para o meio exterior, que faz com que. $\Delta \mathrm{S}_{\text {total }}$ seja maior que zero e a prova é que, na superfície muito mais quente do Sol a energia libertada $-\Delta \mathrm{H}$ já não é suficiente para provocar um $\Delta \mathrm{S}_{\text {total }}$ positivo e o hidrogéneio existe predominantemente sob a forma atómica mais ou menos excitada.

Também a bola de borracha só pára no minimo de energia potencial porque essa é a forma de fornecer mais calor por atrito ao meio exterior. Se não fosse isso, essa posição seria até, de todas, a menos provável. Embora este aspecto se deva manter sempre presente, há conveniência em usar, como já foi dito na aproximação anterior, uma só função que se convencionou ser e se chama energia livre de Gibbs.

Para além de se poder relacionar com as constantes de equilibrio e com potenciais de eléctrodo, tornando-se no auxiliar número 1 do químico para caracterizar a tendência (independente da cinética) dos fenómenos quimicos, esta quantidade, se atendermos a que apenas será estritamente necessário para que a reacção se dê com variação de entropia do Universo não negativa, converter em calor uma parte de $\Delta H$ posta em jogo, exactamente o equivalente a $-\mathrm{T} \Delta \mathrm{S}$, esta quantidade, dizia, assume um novo significado que é o de energia máxima aproveitável sob a forma de trabalho útil. Algumas regras práticas surgem da consideração da aplicação destes princípios aos sistemas reais.

Quanto a estabilidade, a temperaturas baixas prevalecem as formas com baixas energias e grandes espaçamentos entre os níveis quânticos, enquanto que a altas temperaturas prevalecem as espécies de altas energias e pequenos espaçamentos entre os níveis.

Por outro lado, a regra de Berthelot para uma grande parte dos casos do ciclo de Born-Haber, tem razðes para ser aplicada, desde que a temperatura seja suficientemente baixa, ou mesmo a sua versão simplificada da "competição" entre energia de malha e de ionização (as duas componentes mais substanciais da entalpia de formação).

Não se deve esquecer ao trabalhar com energias livres de Gibbs que os cálculos só serão rigorosamente válidos para reacção a pressão constante que é o caso mais vulgar das reacçðes, a céu aberto, no laboratório. Também é muito importante ter em linha de conta que ao contrário do que acontece com a entropia e a entalpia, que não variam muito com a temperatura, as energias livres variam substancialmente e portanto é essencial efectuarem-se as correcçðes.

$\mathrm{O}$ equilibrio quimico é introduzido duma forma empirica, corroborada depois por adequados balanços de entropia, constatando-se mesmo que a lei de Guldberg e Waage não passa da expressão matemática desse balanço.

Quanto ao uso do equilibrio liquido-vapor e das respectivas leis (Trouton e Raoult), atingidas também por balanços de entropia, tem a virtualidade de mostrar que se trata do mesmo tipo de fenómenos que o equilibrio químico - o que em si é importante para a integração da Física e da Química - e também permite a interpretação dos desvios existentes às leis de Trouton e Raoult como prova experimental da existência de forças intermoleculares no estado liquido, nomeadamente as ligaçðes de hidrogénio.

Quanto ao tratamento da cinética, o factor de Boltzmann aparece na génese do conceito de energia de activação, numa Teoria das Colisðes, que é tomada como suficiente a este nivel, se bem que se faça uma discreta referência à Teoria do Estado de Transição. O importante é chamar-se no entanto a atenção para o compromisso - esse sim real - e fazendo parte do quotidiano do químico, entre a termodinâmica especificando as condiçð̃es de equilibrio e a cinética especificando a velocidade com que este é atingido.

$$
-\mathrm{T} \Delta \mathrm{S}_{\text {total }}=\Delta \mathrm{H}-\mathrm{T} \Delta \mathrm{S}
$$

\footnotetext{
* Tem-se $N(d E)=f(E) \times e-E / k T d E$

$f(E)$ - termo quântico

$e^{-E / k T}-$ termo estatistico
} 
APÊNDICE 1

\begin{tabular}{|c|c|c|c|c|c|c|c|c|}
\hline $\begin{array}{c}\begin{array}{c}\text { Número } \\
\text { de }\end{array} \\
\text { lançamentos }\end{array}$ & $\mathrm{n}_{0}$ & $\mathrm{n}_{1}$ & $\mathrm{n}_{2}$ & $\mathrm{n}_{3}$ & $n_{4}$ & $n_{5}$ & $\mathrm{n}_{6}$ & $W=\frac{N !}{n_{0} ! n_{1} !}$ \\
\hline 5 & 5 & 26 & 5 & & & & & $6 \times 10^{10}$ \\
\hline 10 & 7 & 22 & 7 & & & & & $2 \times 10^{14}$ \\
\hline 20 & 13 & 12 & 9 & 2 & & & & $2 \times 10^{17}$ \\
\hline 30 & 17 & 8 & 5 & 6 & & & & $3 \times 10^{17}$ \\
\hline 40 & 16 & 11 & 2 & 7 & & & & $1 \times 10^{17}$ \\
\hline 50 & 17 & 11 & 3 & 2 & 2 & 1 & & $1 \times 10^{18}$ \\
\hline 60 & 16 & 13 & 2 & 2 & 2 & 1 & & $4 \times 10^{17}$ \\
\hline 70 & 20 & 8 & 2 & 2 & 2 & 2 & & $2 \times 10^{17}$ \\
\hline 80 & 18 & 10 & 2 & 3 & 2 & 1 & & $7 \times 10^{17}$ \\
\hline 90 & 20 & 8 & 3 & 1 & 1 & 3 & & $1 \times 10^{17}$ \\
\hline 100 & 19 & 9 & 3 & 2 & 1 & 1 & 1 & $7 \times 10^{17}$ \\
\hline
\end{tabular}

- Muito pequenas mudanças no arranjo original dão lugar a um aumento enorme do número de arranjos da configuração

- $\mathrm{O}$ número de arranjos atinge um máximo - a configuração mais provável $-\mathrm{W}_{\max }-$ à volta do qual o sistema existe

- Uma vez atingido $\mathrm{W}_{\max }$, $\mathrm{W}$ pouco varia.

\section{APÊNDICE 2}

Exercicio de baralhar q quanta por $\mathrm{N}$ particulas

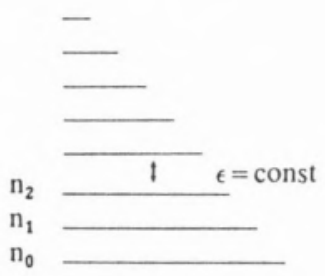

(Constante para cada sistema)

$$
\begin{aligned}
& \frac{\mathrm{n}_{\mathrm{i}}}{\mathrm{n}_{\mathrm{i}-1}}=1 / \mathrm{r}<1 \\
& \mathrm{n}_{0}+\mathrm{n}_{1}+\mathrm{n}_{2}+\ldots=\mathrm{N} \\
& \mathrm{n}_{1}+2 \mathrm{n}_{2}+3 \mathrm{n}_{3}+\ldots=q
\end{aligned}
$$

Substituindo $\left(r^{\prime}=1 / r\right)$

$S=\left(1+r^{\prime}+r^{\prime 2}+r^{\prime 3}+\ldots\right)=\frac{N}{n_{0}}$

$$
T=\left(r^{\prime}+2 r^{\prime 2}+3 r^{\prime 3}+\ldots\right)=\frac{q}{n_{0}}
$$

$$
\lim S=\frac{1}{1-r^{\prime}}
$$

$\lim T=\frac{r^{\prime}}{\left(1-r^{\prime}\right)^{2}}$

Tomando os limites pela soma ( $\mathrm{N}$ e q muito grandes) e substituindo vem

$$
1 / r=\frac{1}{1+\frac{N}{q}} \quad \Rightarrow \quad r=1+\frac{N}{q}
$$

Por outro lado da expressão do número de microestados dum sistema

$\mathrm{W}=\frac{(\mathrm{N}-1+\mathrm{q}) !}{(\mathrm{N}-1) ! \mathrm{q} !}$
Quando se aumenta 1 quantum $q \rightarrow q+1$

$$
W \rightarrow W^{\prime}=\frac{N+q}{q+1} W^{\prime} \simeq\left(1+\frac{N}{q}\right) W
$$

r é o número porque resulta multiplicado o número de microsestados dum sistema quando esse sistema recebe 1 quantum (dividido se cede)

\section{APENDICE 3}

Adicionando um quantum

$$
\begin{aligned}
& W^{\prime}=W \times r \\
& \ln W^{\prime}=\ln W+\operatorname{lnr} \\
& \Delta \ln W=\operatorname{lnr} \\
& \Delta S=k \Delta \ln W=k \operatorname{lnr}-\text { para } 1 \text { quantum }
\end{aligned}
$$

Se o sistema absorver a energia dU, pequena, a ponto de não alterar $\mathrm{r}$ do sistema

$\mathrm{dS}=$ número de quanta $\times \mathrm{k} \operatorname{lnr}=\frac{\mathrm{dU}}{\epsilon} \mathrm{k} 1 \mathrm{nr}=$

$$
=\mathrm{dU} \times \frac{\mathrm{l}}{\mathrm{k} \ln r}=\frac{\mathrm{dU}}{\mathrm{T}}
$$

$\mathrm{T}=\frac{\mathrm{dU}}{\mathrm{dS}} \quad$ Definição macroscópica de temperatura.

\section{BIBLIOGRAFIA}

(1) ATKINS, P.W. - Principles of Physical Chemistry, Cap. II, The Natural Direction of Change: The Second Law, Oxford U.P., 1984.

(2) BENT, H.A. - The Second Law, Cap. 20-36, Oxford U.P., 1965.

(3) BLACK, P.J., DAVIES, P., OGBORN, J. - A Quantum Shuffling Game, for Teaching Statistical Mechanics, Am. J. Phys. Vol. 39, 1154, 1971.

(4) BRUNER, J.S. - Towards a Theory of Instruction, New York, Norton, 1966.

(5) EINSTEIN, A., INFELD, L. - A Evolução da Física, Livros do Brasil, 1972.

(6) FEYNMAN, R.P., et al - The Feynman Lectures, Vol. 1, Addison Wesley, 1963.

(7) GURNEY, R.W. - Introduction to Statistical Mechanics McGraw Hill, 1966.

(8) Nuffield Advanced Chemistry Teacher's Guide I Longman, 1984 (Revised).

(9) Nuffield Advanced Physics, Unit 9 - Change and Chance, Longman, 1979 (Revised).

(10) OGBORN, J - - The Second Law of Thermodynamics: A Teaching Problem and Opportunity, School Science Review - June 1976.

(11) OGBORN, J. - Dialogue Concerning Two Old Sciences, J. Phys. Ed. 2, 272-276, 1976.

(12) Open University - Course S100 Science Foundation Course; Unit 5 the States of Matter; Units 11, 12 Chemical Reactions, Open University Press, 1971.

(13) PIAGET, J., INHELDER, B. - The Growth of Topical Thinking, New York, Baria Books, 1958.

(14) PSSC - College Physics, Raytheon, 1968.

(15) RIEF, F. - Statistical Physics: Berkeley Physics Course, Vol. 5, McGraw Hill, 1965.

(16) SOLOMON, J. - How Children Learn About Energy or Does the First Law Come First? School Science Review, 63, 415-422, 1982.

(17) WYATT, P.A.H. - The Molecular Basics of Entropy and Chemical Equilibrium, R.I.C., Monographs for Teachers, n. ${ }^{\circ} 19$, 1971. 